THE ELPHINSTONE.VINCENT DYNAMO ELECTRIC simple phenomenon is based the whole of the recent import- of Manchester, bit upon an important improvement by conMACHINE.

ant de velopment in electrical science, and to Faraday we owe the credit of having laid the foundation of the many
useful inventions by means of which electric lighting, as SEVERAL of these dybamo electric machines bave just been
constructed, and we understand, says the Electrical Revievo,
well as the transmission of power, and the propulsion of of
bat their efficiency is very bigh, but in the absence of any
tramears by electricity, has been made practicable to-day. that their efficiency is very high, but in the absence of any data we can only make this statement with reserve. The
machine here illustrated weighs complete about 26 or 27 cwt., machine here illustrated weighs complete about 26 or $27 \mathrm{cwt}$.
and is constructed for working 400 incandescence lamps. It will be seen that three $\mathbf{V}$ shaped electro-magnets surround nately. Inside the arnature is an iron spindle carrying six
internal electro-magnets of similar polarity to those above.
The armature is not coiled with wire, as is usually the case, but flat hollow parallelograms of double wire are constructed and laid on the outside surface of the armature drum, which
is formed of a kind of papier-mache. These parallelograms is formed of a kind of papier-mache. These parallelograms
of wire are laid all around the drum, overlapping each other, and they are firmly bound down with string or any suitable binding.

The ends of the wire coils are connected up with a comumtator in all respects similar to tbat employed in the Gramme

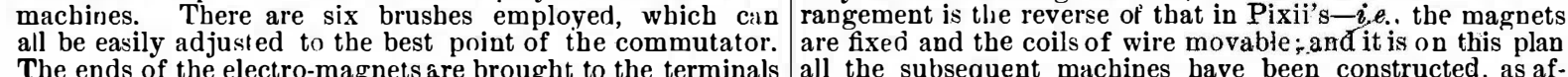

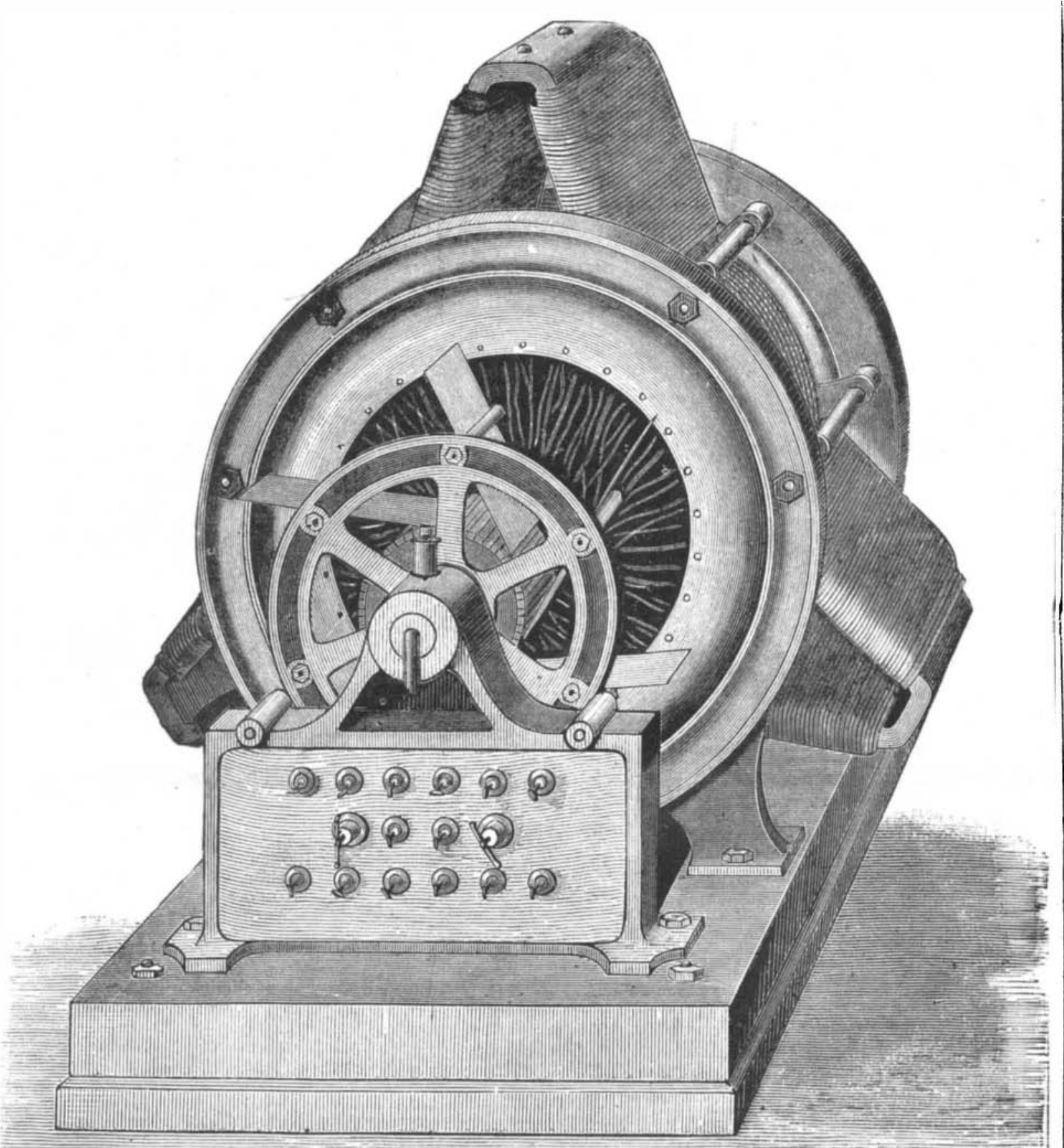

THE ELPHINSTONE.VINCENT DYNAMO ELECTRIC MACHINE.

seen on tbe face of the machine-the inside ones through the fording better results than where the coils are stationary and spindle-so that any desired coupling may be made. There the magnets movable. The lit tle magneto machines still sold we shall fully deal with shortly.

The arrangement of the amature drum, its coils, and the Following the inventions of Saston and Clarke are those electro-magnets forms the chief feature in the machine, for which, however, are now rarely used in this country, and we it is by means of this that the external and internal poles of shall not, therefore, dwell upon them, but basten on to the the electro-magnets are brought very near together, thus forming a magnetic field of great intensity, through which the
coils of wire on the surface of the armature drum pass.

ON MAGNETO-ELECTRIC AND DYNAMO-ELECTRIC MACHINES

By J. ANgelo Fahie, Inst. C. E., Ireland.

Furaday's Discovery.-In the year 1831, the illustrious Faradiy made the important discovery, that by moving a city was generated in the coil, or, vice versa, by moving the magnet and bolding the coil stationary a like result was obtained; thus a current of electricity was obtained, either by moving a wire in the presence of a stationary magnet, or by
moving a magnet in the presence of a stationary wire. The in. moving a magniet in the presence of a stationary wire. The in. of the magnetism nresent, and (2) on the velocity with which
the coil was moved tlirough the magnetic field. Upon this

${ }^{*}$ Abs ract of paper read before the Inst. C. E., Ireland. striacting a machine consisting practically of two Siemen
machines combined-a large and a small one; and in the machines combined - a large and a small one; and in the stituted electro-magnets, which be caused to be excited by the current produced by the smaller one. By this arrangement considerably more powerful currents were obtained than by any of the machines previously constructed.
Siemens' and Wheatstone's Discovery. ${ }^{*}$-Next in the order Siemens' and Wheatstone's Discovery. - Next in the order
of remarkable electrical phenomena comes the important discovery made simultaneously, but independently, by $\mathrm{Dr}$. Siemens and Sir C. Wheatsione-a discovery which marks the transition of the magneto-electric machine to that type most in practice at present- the dynamo macline, called for convenience the dynamo. What Dr. Siemens and Sir C. Wheatstone discovered was this: That a current of electri-
city could be generated in the coils on the armature by the city could be generated in the coils on the armature by the magnets, and that by passing this feelle current round the magnets, their magnetism would be strengthened, which in turn would produce a stronger current in the armature, and this current would again react on the magnets. rendering them more powerful, this action going on until the limit of saturation is attained; for it must be understood that this ism in the iron cores cannot be intensified beyond a certain point, and this point depends on and is controlled by the
scientific conditions on which the macline is constructed. Among the several machines constructed on the princip discovered by Siemens and W constructed on the principle are those of Gramme, Siemens, Edison, Brush, Burgin, and Gulcher. They differ chiefly in the construction of the armature and the arrangement of the electro-magnets. The electrnmotive force generated in each of them is proportional
to the number of turns of wire in the rotating armature, and to the number of turns of wire in the rotating armature, and, small electromotive force, but of considerable quantity, are obtained by making up the armature of only a few turns of stout wire, or bars of copper (as in the Edison machine) offering only a slight internal resistance. Currents of bigh electromotive force are produced by forming the armatur
of many coils of very fine wire and driving it very fast. The term electromotive force may be compared to the pressure of water, being the electric condition necessary to over-
come the external resistance of the circuit, just as a given peferer to its flow-for instance, to move the plunger of a bydraulic press; and as a given quantity of water under pressure is required to keep the plunger moving so a given quantity of electricity under a given electromotive force is required to keep the lamp burning or the electro-motor moving, as the case may be. The unit of electromotive force is termed a volt, which is approximately equal to the force of a
Daniell cell; the unit of resistance is an ohm, which is the Daniell cell; the unit of resistance is an ohm, which is the wire 10 feet long by 10 millimeters in diameter; and the unit of current, the ampère, which is one volt passing through on and is represented by the equation.

$$
\mathrm{C}=\frac{\mathrm{E}}{\mathrm{R}} \text { : }
$$

$\mathrm{C}$ being current, or ampète; $\mathrm{E}$ being electromotive force, or volt; $\mathbf{R}$ being resistance, or ohm.

lat electronorth poles facing one another and united hy arched piece united. In the space thus formed between the upper aud witer magnets the armature rotates, consisting of a cylinder round which are wound longitudinally a number of coils in a peculiar maner, and crossing over each other at all angles at both ends of the cylinder, each end of each coil being con forming the commutator. It will be observed that in this machine the $t$ wo poles of the field magnets act simultaneously on each coil, and the double action oper ting on opposite
sides of the coil, where the current bas a contrary direction.

Edison's Machine.-The next important development which we shall notice in the Siemens ype of generators is
that of Edison, who has succeeded in applying to practice the largest dynamo yet constructed. Its total weiglit is about the armature shaft), and it is capable of $y 00$ ampères. An
idea of its colossal size may be formed by comparing it with the largest. Gramme made. which weighs only about one ton. and yields a current of only $90 \mathrm{amperes}$.
The Edison armature resembles in form that of Siemens, The Edison armature resembles in form that of Siemens,
but differs essentially in the method of its construction. The ir $\because n$ core is built up of a number of sheet-iron dikss, or
washers, insulated from each other and bolted firmly towashers, insulated from each other and bolted firmly to-
gether by bolts passing through them in a line parallel to the axis of the core. This method gives the advantage of a solid iron core, and prevents the circulation of local currents which are usually set up in solid cores, causing a loss of
power. Instead of the usual insulated wire, the coils are composed of heavy copper bars or prisms, longitudirally arranged, and insulated tro core underneath, and these bars are connected at each end

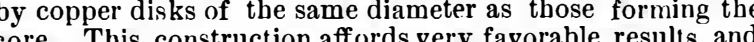
the resistance of the armature is reduced to a minimum. while, owing to the annular space between the bars and the core, a free circulation of air is maintained, thereby reducing the tendency to beat and increasing the capacity of the machine. Edison uses long cylindrical masses of metal for wire; and by this arrangement he claims to secure a mor powerfur magnetic field than by using the same weight of metal of shorter length. gested the use of an iron ring wound round with insulated wire, which be caused to rotate between the poles of permanent steel magnets. The object of Pacrinotti was, bowever, rather to proriuce an electro-motor engine than a machine for generating electric currents; and the advantages of the ring armature remained therefore unrecognized until it found its first practical application in the invention of M. Gramme,
of Paris, as introduced and described before the French Academy of Sciences in 1871.

The Gramme Machine is generally considered the simplest form of apparatus for generating electricity hy mechanical means. At any rate, its action is easily understood. Around
the soft iron ring, which forms the core of its armature, a - Mr. Fahie, like many others, apparently gnores the claims of $\mathrm{Mr} . \mathrm{S}$.
A. Varley conjointly with those of Wheatstone and siemens in regard ti 


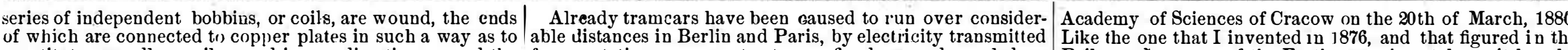
constitute an endless coil wound in one direction around the ring. The plates are insulated from each other, and so arranged as to form a commutator. This ring is caused to ro.
tate between two powerful electro-magnets, each provided late between two powerful electro-magnets, each provided
with polar extensions overlapping about two thirds of the currents generated in the coils, and the currents flowing from the machine are caught up by brusbes or combs whicl press on the commutator. The Gramme machine is very popular, and is extensively
used both in England and on the Continent.

The Brush Machine.-Closely resembling the Gramme in struction and action. is that known as the Brush dynamo. States and England. For currents of ligh electromotive force the Brush macline is considered a gond one Its armature, though consisting of a ring like that of $\mathrm{Gr}$ mme's, is, however, differently "built up." At intervals around the wound the coils or bobbins, all in the samedirection; a nd instead of forming a continuous circuit, as in the Gramme, each other by one end of each coil, while the other ends of the pair ( $i e$, the ends conveying the current) are connected to the commutator in such a manner that a portion of the
current flows to the external circuit through one pair of brusbes, while another portion of the current is conveyed round the electro-magnets by another pair of brushes. One
coil of each pair, in fact, feeds the external circuit, while the opposite coil simultaneously magnetizes the field magnets tield. practical form of electric generator, is the invention of $\mathrm{ML}$ Bürgin, of Switzerland. Its peculiarity lies in the construction of its armature, which, instead of being a single ring as in the Gramme, is made up of several hexagonal frames mounted parallel to each other on the same spindle, and
around each of these frames are wound a series of bohbins around each of these frames are wound a series of bohbins
or coils as in the Gramme ring. " By increasing the number or coils as in the Gramme ring. . By increasing the number
of these framês and lengthening the electro-magnets a higher electromotive force can be readily obtained. This armature is considered very simple in construction, easy of repair, and up is somewhat complicated and difficult to explain. The free access of air to the exposed surfaces of the frames prevents the coils being unduly beated by the current. This, at first sight, appears to be an advantage possessed both by
the Brush and Bürgin machines over the ordinary Gramme, the armature of the latter being so closely and so thickly driven at a high speed. This advantage is, however questionable when it is remembered that since the ring in the one case is only partially surrounded with coils, in the other case it is completely enveloped. Sothat for rings of the same size, and driven at the same speed, the Gramme certainly gives out the greatest stream of electricity. The electroby the induced currants similar to the Siemens and Gramme machines.

The Giilcher Machine. - The last machine of the purely ring type worthy of note here is that known as the Gülcher, which type worthy. of note here is that known as the Gulcher, which that it is provided with fifty-two sections of wire, and rotates between eight field magnets-four on each side. It is also provided with a new feature consisting of troughs or shoes,
forming three sides of a square fixed round the ring, so that not only the sides of the revolving bobbins are under magnetic influence but also their peripheries. and Alliance types, and is the only one at present in use which contains permanent steel maynets, all the other electric generators of recent construction containing the more compact and powerful electro magnets. In construction the De Meritens machine consists of a Gram me ring armature,
mounted on a spindle and rotated witbin a circular frame, on which are placed horizontally a series of powerful steel horsesboe magnets on the principle of the earlier form of the Alliance machines. It gives alternating currents, and its coils can be connected in various ways so as to give tension or quantity currents, as may be required. Great efficiency simple and effective, and it is greatly liked by the British lighthouse autborities.

The use of dynamo machines in the generation of electri. city for public illumination has now been sufficiently demon-
strated to be both practicable and economical, especially in large areas where corisiderable light is required, such as rail. way stations, harbors, and public institutions, not to men-
tion lighthouses, in which the electric light has been used with advantage for a number of years; and again in military operations dynamo machines play an important part in producing the intense light required for illuminating at night a
distant point to observed, or ligbting up the work of the as. distant point to observed, or ligbting up the work of the as.
sailants in sieges. Evidence of their utility in this direction (in connection with the militar operations during the late campaign in Egypt. light, probably the most useful purpose to which the dynamo has yet been applied is the transmission of power. This property depends on the principle known as the reversibility
of the dynamo, or, in other words, the transformation of elecrical energy into mechanical work, which is simply the conerse of what we have been bitherto considering in regard In the transmission of power ly electricity the current is generated in one machine, from which it is conveyed to an-
other, which mav be at any distance, and may be utilized to set machinery of any kind in motion.

The distance over which the electric transmission of power may be carried without serious loss of energy is still a mat-

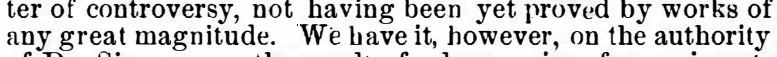
Dr. Siemens, as the result of a long series of experiments version of mechanical into electrical energy and i.e., the conconversion of electrical into mechatical work) is about 20 per cent. To this loss should be added that caused by the resistance of the wires, which depends on their length and sectional area, so that for actial work it is cousidered safe does not exceed 50 per cent., which will not appear very great when compared with the loss sustained in transmit ting power by compressed sir, water, or other means.
Already tramcars have been Gaused to run over consider-
ble distances in Berlin and Paris, by electricity transmitted
rom a stationary generator to one fixed on and coupled up with the axle of the moving velicle. And in our own counthe we shall soon, let us hope, have the pleasure of seeing conomically the principle involved in the electric transmison of power to a distance. In the electric railway now in it is proposed to mount an electro-motor on eacb car, which conductor laid along the rails, the rails themselves forming the return circuit.

It will he. a matter of congratulation to the enterprise and cessful, it being the first work on a large scale of the kind In conclusion, the autbor trusted that he bad succeeded in mparting some idea of the fundamental principles and con-
struction, as well as of the useful applications of magnetoelectric and dynamo-electric machines, through the agency vast power stored up in great waterfalls, in the perpetual ow of our rivers, in the rise and fall of our tides, and in the viceable to the wants and conveniences of man.

IMPROVED ELECTRIC BELL AND BATTERY. AN impróved form of electric bell has been recently in-
vented by M. J. Siegel, of Briunn. As a rule, electric bell are so constructed that the armature is attached to a spring g plate, and carries a long projecting arm and knob called bell. Such bells are usually fitted by placing the electroagnets and armature in a wood case, leaving the hacinmer ranged to work on a pivot or pivots, and the patentee contructs the same, especially for larger bells, in two parts, one of which carries the knob, and receives its action by
means of a lever from the other part It will be seen that

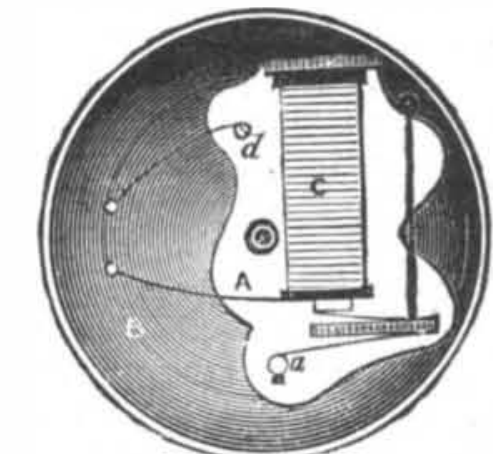

COMBINED BATTERY AND BELL
Like the one that I invented in 1876 , and that figured in the Railway Company of the East's experimental car, it has the A model designed forthe demonstration of this sort of total izing integrator is shown in the annexed figure. Its essential parts are as follows:

1. A cylinder mounted on points and capable of being moved in a direction parallel with its axis of rotation; the prints around which it revolves being for this purpose connected to
a frame, $M H M^{\prime} E$, which is carried by friction rollers, GG, running on rails, $R R^{\prime}$.
2 . A roller, $r$, applied against the cylinder by a spring which presses continuously against the rod, $t s$, which is movs, between whose branches revolves the axle of the ioller. The mounting of this latter, as may be seen, resembles that of the steering wheel of a tricycle.

This roller may thus assume two rotating motions-one axis, st. The latter motion is given it by means of a rod, $t \mathrm{~V}$, wand, being given an arbitrary motion, whose extent may be measured by means of the needle, $\mathrm{H}$, which is movable If we designate by

the angle that the horizontal axis of the roller makes

the infinitely small space traversed by the frame

MH infinitely small space traversed by the frame

ment of time, $d t$; by
the linear arc described by the circumference of the cylinder, $\mathrm{C}$, during the same time; and by

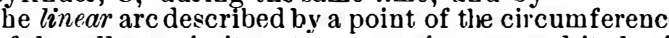
of the roller, $r$, in its rotatory motion around its hori-
zon'al axis, it is easy to demonstrate that we have between these four
quantities the two relations

$$
\begin{aligned}
& d x=d x \operatorname{tg} a \\
& d z=\frac{d x}{\cos a}
\end{aligned}
$$

This latter relation has no interest as regards the question that occupies us, but the first gives

$$
y=\int d x \operatorname{tg} a .
$$

Consequently, if $x$, that is to say, the space traversed horizontally by the frame, is proportional to the time, $t$ (this being obtained by a clockwork movement), and if tga is
proportional to the product, EI, of the difference of poten proportional to the product, EL, of the difference of potencirculating between such points (it being possible to obtain this by my measurer of energy), we obtain, on multiplying a this by my measurer of energy), we obtain, on multiplying a
constant, $K$, which depends on the construction of the apparatus,

$$
y=k \int \mathrm{EI} d t
$$

Then the angles described by the cylinder, C, around its axis by this simple arrangement a more correct striking, without are proportional to the quantities of energy expended during horter lammer, a much louder tone.- The electro-magnet, this apparatus and the one thathas been adopted by Mr. Boys.

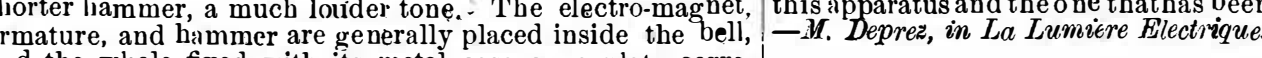

and the whole fixed with its metal case on a plate corremprovement is that, whereas in the usual form of electric bells the action of the hammer must be adjusted by mean of a screw, by this invention it is possible to turn more or
less the whole apparatus round its axis, and so use the cener of gravity of the bammer to regulate the action accord mproved hattery consists simply of a zinc rod and a cylin er or block formed of a mixture of carbon and manganese o which is added a proportion of iron filings, oxide of iron oxide of copper by means of moulds and pressure. The his arrangement a powerful and constant current is obained. The battery acts at once by contact with the solu-
ion, and is almost everlasting, as the combination block

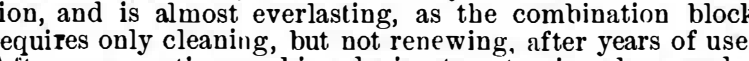
After comparative working during twenty-nine days under ies, and one of the above construction, the patentee found that the former lost twenty-four per cent. of its strength,
and the latter remained almost nominal, as at starting. In and the latter remained almost nominal, as at starting. In ard to which the bell is secured; $B$, the outline of gong; $C$, ABAKANOWICZ'S TOTALIZING INTEGRATOR.

ABAKANOWICZ'S TOTALIZING INTEGRATOR. The totalizer adopted by Mr. Vernon Boys is identical
with that which Mr. Abdank Abakanowicz presented to the

\section{COMMERCIAL ALBUMEN.*}

By Alfred H. Allen.

THE applications of albumen are now very numerous, and as it differs much in quality, according to its origin and the
details of its preparation, it is sometimes necessary to ascertain its purity and freedom from adulteration.

Commercial albumen is obtained chiefly from two sources egga. and the serum of blood. Fish-abumen is also met
with occasionally, and may be recognized by its fishy Blood or serum-albumen is obtained by separating the
Blog erum from the clot of perfectly fresb blood. The liquid is evaporated in slallow trays, at a temperature not exceeding
$50^{\circ} \mathrm{C}$., when the albumen is obtained in brittle scales or transparent flakes of a grayish, yellowish, reddish, brown, or black color. The qualities of serum-albumen, mnde by leading firms, are "refined," " prime," "No. 1," "No. 8," and is of a dirty yellow color, and, like prime, is employed
for printing delicate colors. No. 1 is darker in color and for printing delicate colors. No. 1 is darker in color and poses. No. 2 quality is made from the second draining of siphoned off, is more or less tinged with red, and consequently is only fit for printing dark colors; as a rule, it

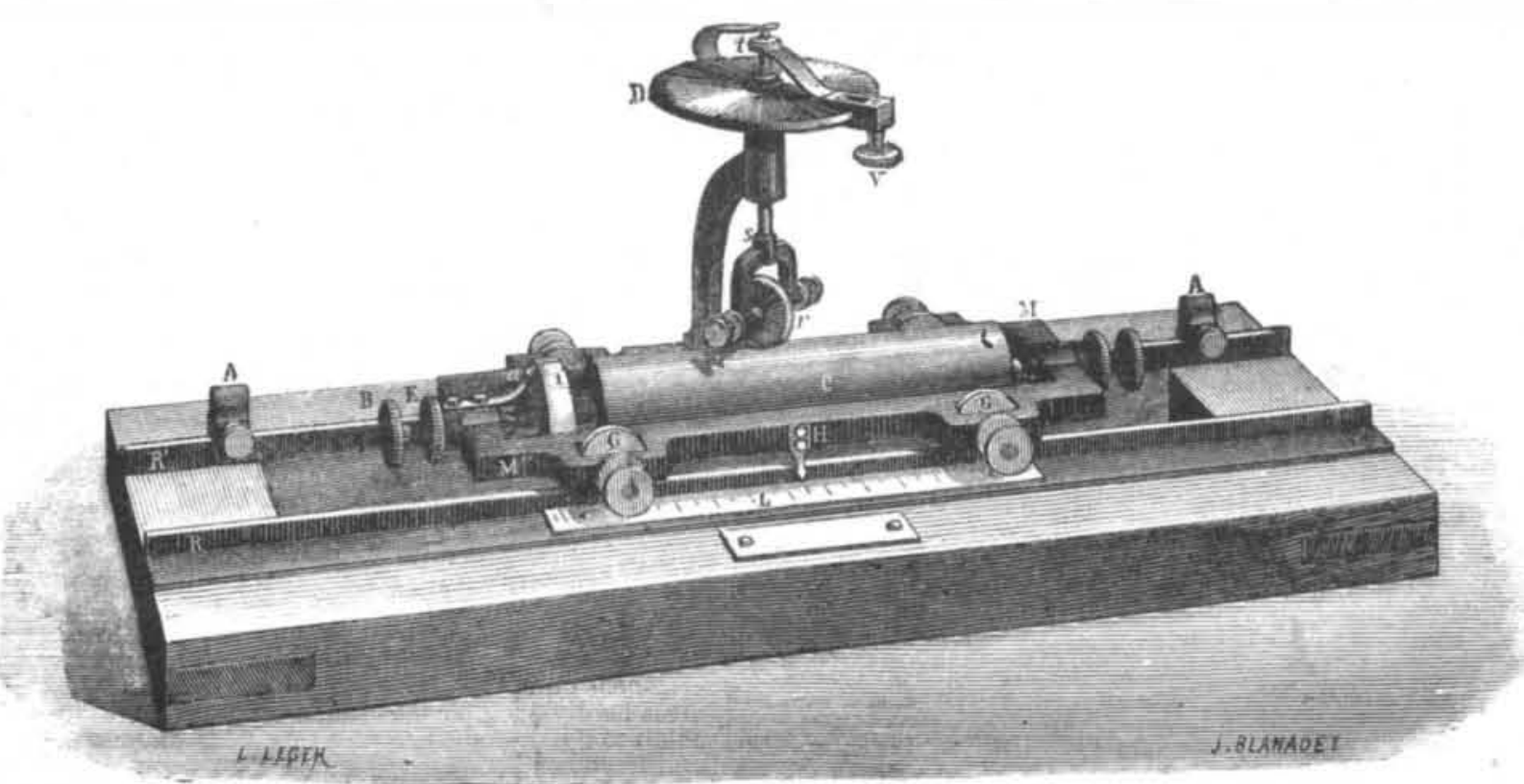

ABAKANOWICZ'S TOTALIZING INTEGRATOR. 